\title{
Oxygen Saturation Index and Severity of Hypoxic Respiratory Failure
}

\author{
Munmun Rawat ${ }^{\mathrm{a}}$ Praveen K. Chandrasekharan $^{\mathrm{a}}$ Ashley Williams $^{\mathrm{a}}$ \\ Sylvia Gugino ${ }^{a}$ Carmon Koenigsknecht $^{\mathrm{a}}$ Daniel Swart ${ }^{\mathrm{a}}$ Chang Xing Ma $^{\mathrm{b}}$ \\ Bobby Mathew $^{\mathrm{a}}$ Jayasree Nair ${ }^{\mathrm{a}}$ Satyan Lakshminrusimha ${ }^{\mathrm{a}}$ \\ ${ }^{a}$ Division of Neonatology, Department of Pediatrics, and ${ }^{\text {b }}$ Department of Biostatistics, University at Buffalo, \\ Buffalo, N.Y., USA
}

\section{Key Words}

Oxygenation index . Pulmonary vascular resistance .

Pulmonary hypertension

\begin{abstract}
Background: The oxygenation index $(\mathrm{Ol}=$ mean airway pressure, MAP $\times \mathrm{FiO}_{2} \times 100: \mathrm{PaO}_{2}$ ) is used to assess the severity of hypoxic respiratory failure (HRF) and persistent pulmonary hypertension of the newborn (PPHN). An indwelling arterial line or arterial punctures are necessary to obtain $\mathrm{PaO}_{2}$ for the calculation of OI. Oxygenation can be continuously and noninvasively assessed using pulse oximetry. The use of the oxygen saturation index $\left(\mathrm{OSI}=\mathrm{MAP} \times \mathrm{FiO}_{2} \times\right.$ $100: \mathrm{SpO}_{2}$ ) can be an alternate method of assessing the severity of HRF. Objective: To evaluate the correlation between OSI and OI in the following: (1) neonates with HRF and (2) a lamb model of meconium aspiration syndrome. Methods: Human neonates: a retrospective chart review of 74 ventilated late preterm/term neonates with indwelling arterial access and $\mathrm{SpO}_{2}$ values in the first $24 \mathrm{~h}$ of life was conducted. OSI and OI were calculated and correlated. Lamb model: arterial blood gases were drawn and preductal $\mathrm{SpO}_{2}$ was documented in 40 term newborn lambs with asphyxia
\end{abstract}

and meconium aspiration. OI and OSI were calculated and correlated with pulmonary vascular resistance (PVR). Results: Mean values of OSI and OI showed a correlation coefficient of 0.952 in neonates (mean value of 308 observations in 74 neonates) and 0.948 in lambs (mean value of 743 observations in 40 lambs). In lambs, with increasing PVR, there was a decrease in OI and OSI. Conclusion: OSI correlates significantly with OI in infants with HRF. This noninvasive measure may be used to assess the severity of HRF and PPHN in neonates without arterial access.

(c) 2015 S. Karger AG, Basel

\section{Introduction}

The oxygenation index (OI) is commonly used to assess the severity of hypoxic respiratory failure (HRF) and persistent pulmonary hypertension of the newborn (PPHN) in neonatal intensive care units (NICU). This index is considered a better indicator of lung injury compared to the $\mathrm{PaO}_{2} / \mathrm{FiO}_{2}$ ratio as it includes mean airway pressure (MAP) - an important determinant of oxygenation [1]. Both clinical practice guidelines and research trials evaluating the use of therapies for HRF and PPHN

\section{KARGER 125}

(c) 2015 S. Karger AG, Basel

1661-7800/15/1073-0161\$39.50/0

E-Mail karger@karger.com

www.karger.com/neo
Munmun Rawat, MBBS

Division of Neonatology, Women and Children's Hospital

University at Buffalo, 219 Bryant Street

Buffalo, NY 14222 (USA)

E-Mail munmunra@buffalo.edu 
Fig. 1. a Scatter plot showing mean OI and OSI in late preterm and term neonates with HRF during the first $24 \mathrm{~h}$ of life. The axes for OI and OSI are on a logarithmic scale to a base of 2. b Scatter plot showing all observations of OI and OSI in late preterm and term neonates with HRF during the first $24 \mathrm{~h}$ of life. The axes for OI and OSI are on a logarithmic scale to a base of 2 .
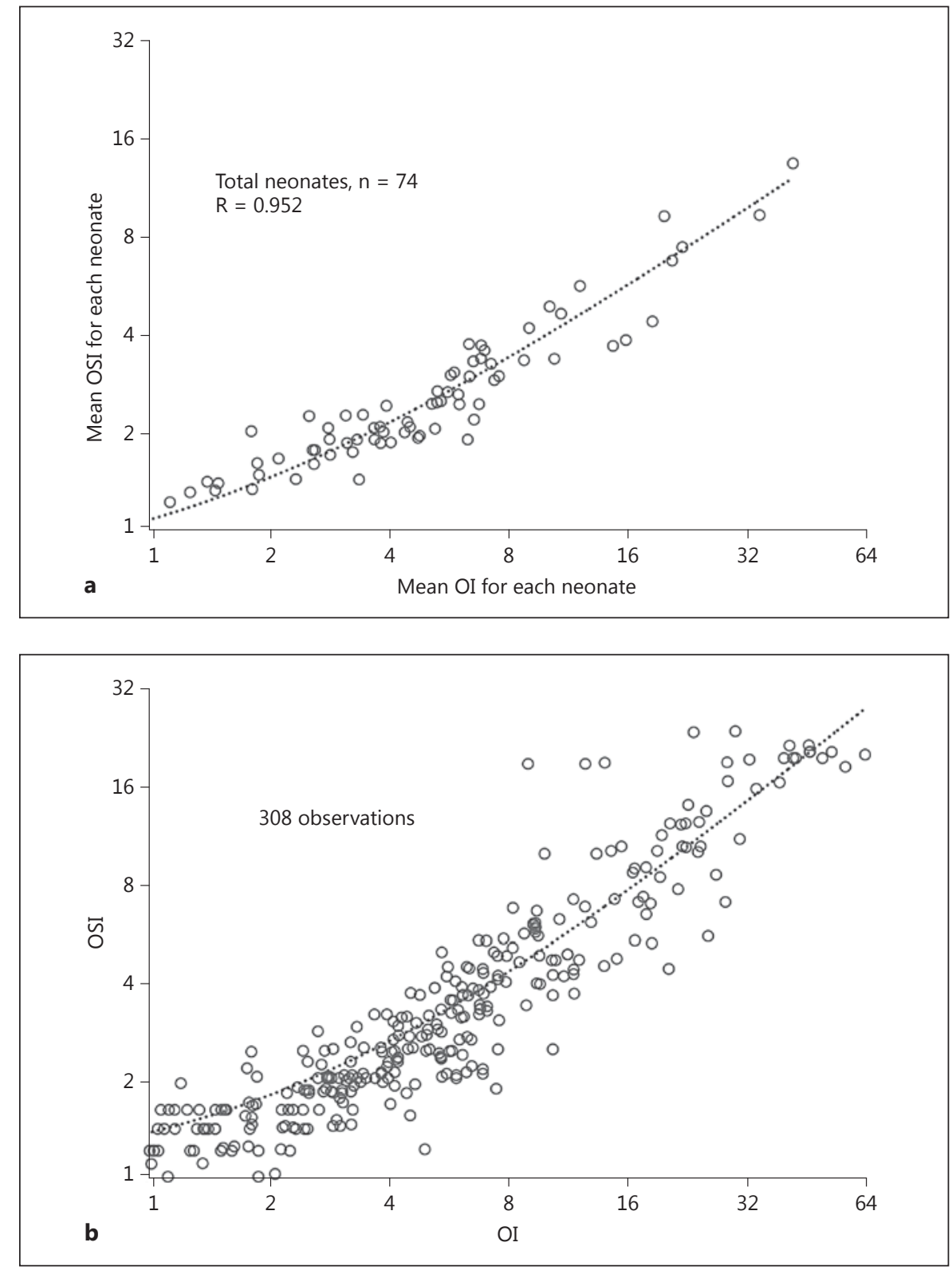

have adopted OI to define entry criteria and assess outcome [2-5]. It is common practice to use OI to dictate management such as the initiation of inhaled nitric oxide and the need for surfactant and extracorporeal membrane oxygenation (ECMO). The oxygenation index is calculated by the following equation: MAP (in $\left.\mathrm{cm}_{2} \mathrm{O}\right) \times \mathrm{FiO}_{2} \times$ $100: \mathrm{PaO}_{2}$. There are several disadvantages to the use of $\mathrm{OI}$ in the NICU. It is invasive and requires an indwelling arterial line or arterial puncture to obtain a blood gas sample. It is only intermittently measured when blood gases are obtained. The site of sampling is decided by the loca- tion of the arterial line (e.g. only postductal gases can be obtained if an umbilical arterial line is present and the postductal $\mathrm{PaO}_{2}$ might be considerably lower than the preductal $\mathrm{PaO}_{2}$, perfusing the heart and brain). Finally, it is not known if OI correlates with the severity of lung disease or pulmonary vascular resistance (PVR) in PPHN.

Recently, studies from pediatric critical care units have suggested the use of the oxygen saturation index (OSI) [1] or saturation to $\mathrm{FiO}_{2}$ ratios [6] for assessing the severity of HRF and acute respiratory distress syndrome or acute lung injury. We evaluated the correlation between OI and 
Fig. 2. a Scatter plot showing mean OI and OSI in term lambs with asphyxia and meconium aspiration and PPHN. The axes for OI and OSI are on a logarithmic scale to a base of 2. b Scatter plot showing all observations of OI and OSI in term lambs with asphyxia and meconium aspiration and PPHN. The axes for OI and OSI are on a logarithmic scale to a base of 2 .
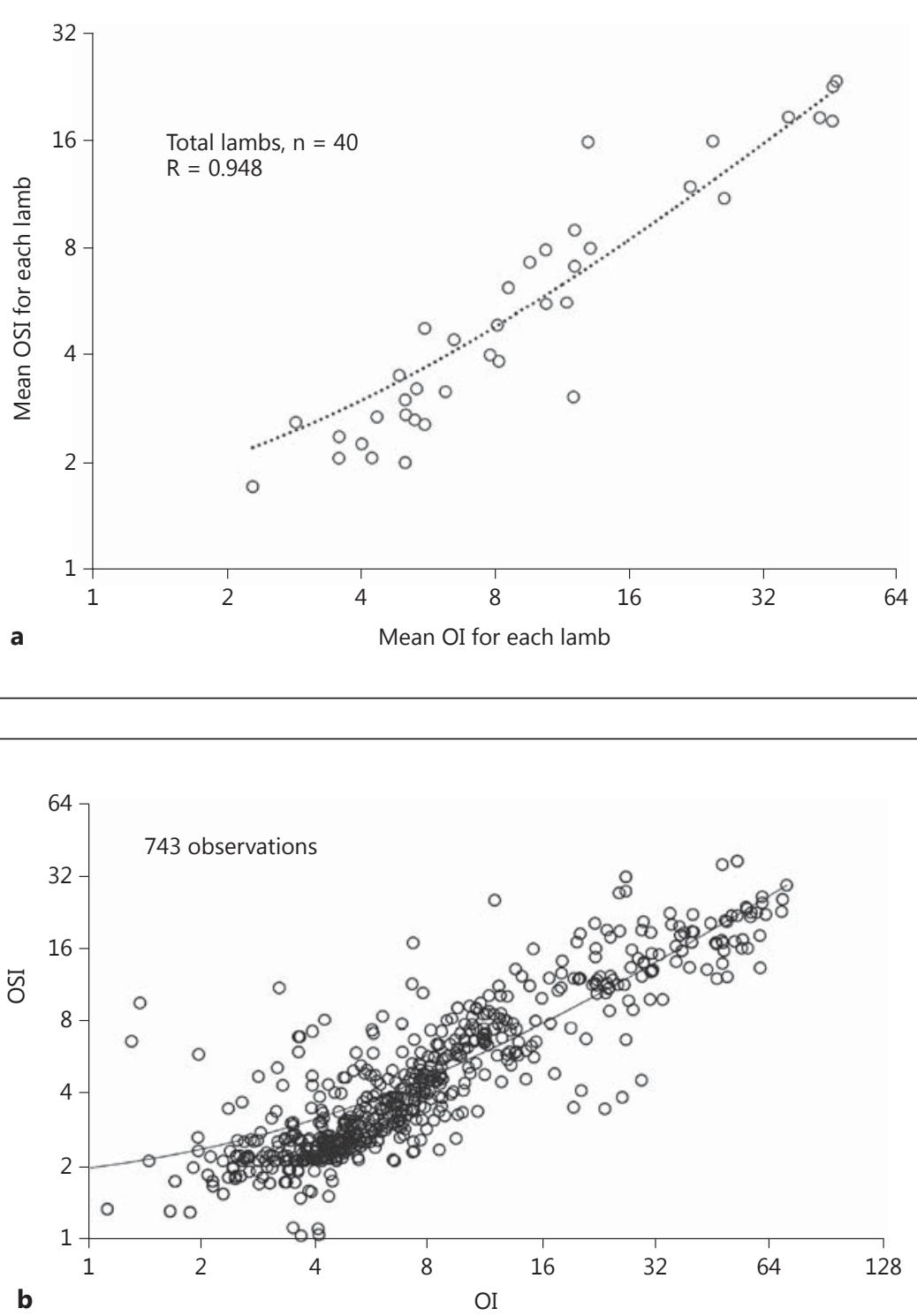

b
OSI $\left(\mathrm{MAP} \times \mathrm{FiO}_{2} \times 100: \mathrm{SpO}_{2}\right)$ in human neonates with $\mathrm{HRF}$ and lambs with meconium aspiration syndrome (MAS). We hypothesize that OI and OSI correlate well with each other but neither index correlates well with PVR in HRF/PPHN.

\section{Methods}

Neonates with HRF

A retrospective chart review was conducted in neonates born between September 2011 and May 2014 and admitted to the
NICU at The Women and Children's Hospital of Buffalo. The study was approved by the Children and Youth Institutional Review Board of the State University of New York at Buffalo. Data were extracted from electronic medical records. Infants $\geq 34$ weeks of gestation who required intubation and mechanical ventilation and had at least one arterial blood gas on the first day of life and a corresponding saturation value (Masimo Radical 7 pulse oximeter; Masimo Inc., Irvine, Calif., USA) recorded simultaneously were included. Arterial blood gases in the first $24 \mathrm{~h}$ of life and corresponding oxygen saturations were collected in 74 infants. Ventilator settings at the time of blood gas draw were recorded. OI and OSI were calculated using the formulae listed above. 
Fig. 3. Graph depicting trends of OI, OSI and oxygen saturations in relation to PVR.

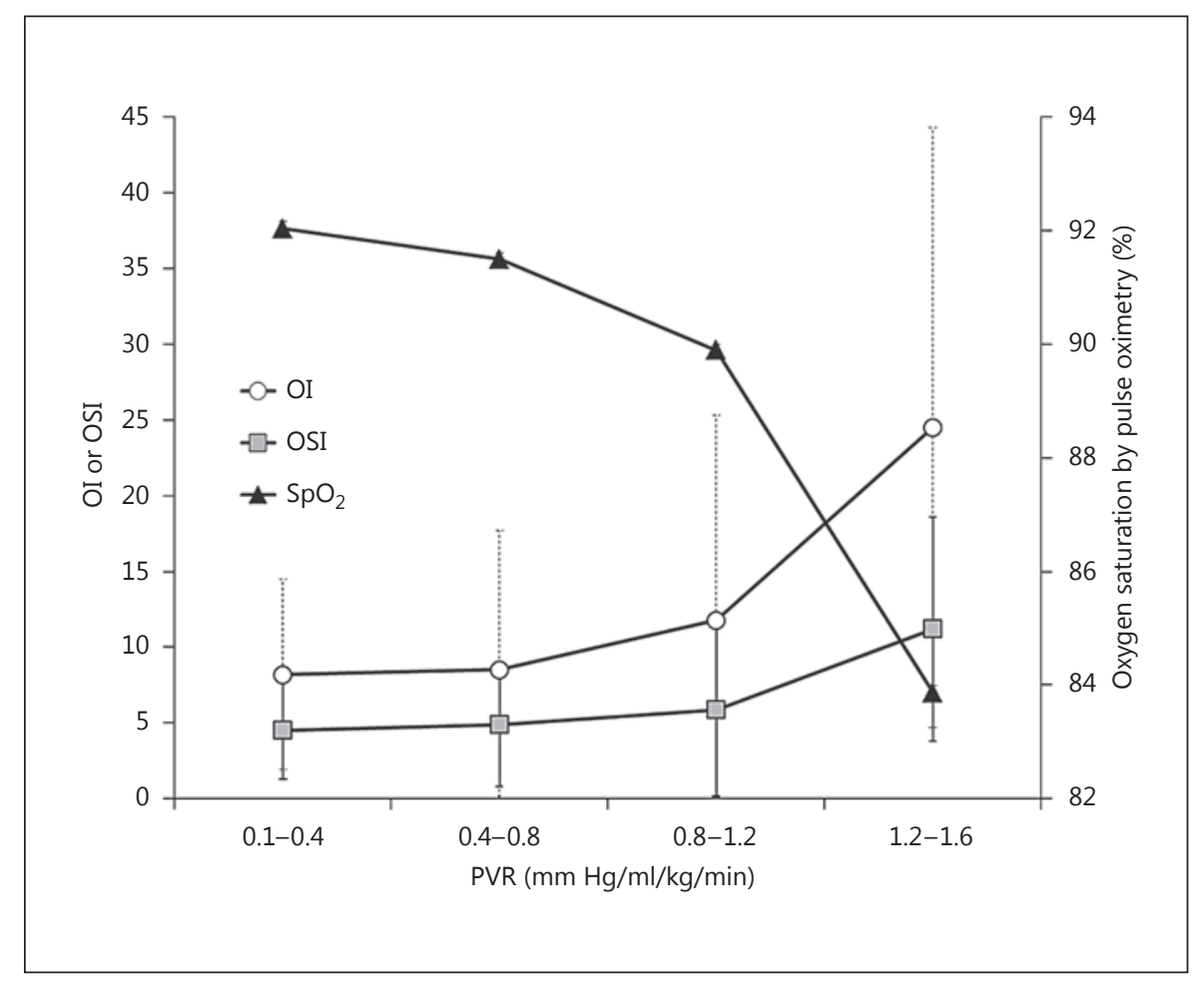

\section{Lamb Protocol}

This study was approved by the Institutional Animal Care and Use Committee at the State University of New York at Buffalo. A total of 40 time-dated pregnant ewes (139-142 days of gestation; term: 145 days; Newlife Pastures, Attica, N.Y., USA) were sedated, intubated and ventilated with $2 \%$ isoflurane. Jugular and carotid lines were placed on the right side for access, drawing preductal blood gases and blood pressure monitoring. Catheters were placed in the main pulmonary artery and left atrium for pressure monitoring, as previously described $[7,8]$. The Masimo Radical 7 pulse oximeter was attached to the right forelimb to monitor preductal $\mathrm{SpO}_{2}$. Fetal lambs were asphyxiated by umbilical cord occlusion and meconium was instilled into their endotracheal tube, as previously described [9]. The lambs were then delivered, ventilated and blood gases were obtained at $30 \mathrm{~min}$ of age and then every $15 \mathrm{~min}$ until $6 \mathrm{~h}$. The preductal $\mathrm{SpO}_{2}$ was monitored and recorded continuously. OI, OSI and PVR were calculated. PVR was calculated by the following formula: PVR $=$ (mean pulmonary arterial pressure - mean left atrial pressure) : left pulmonary blood flow corrected for body weight.

\section{Statistical Analysis}

OI and OSI for different saturation ranges were analyzed using correlation coefficients (Pearson's correlation) and calculated with the use of linear regression techniques. Average OI and OSI values for each lamb and neonate were used to represent repeated measures. Data were analyzed by a mixed effect model (LME model) with SAS 9.0 (SAS Institute, Cary, N.C., USA) [10].

\section{Results}

\section{Correlation between OI and OSI}

Human Neonates with HRF

Data were collected from 74 neonates admitted to NICU with HRF between September 2011 and May 2014. A total of 308 observations with simultaneous $\mathrm{SpO}_{2}$ (either preductal or postductal), ventilator settings and arterial blood gases were recorded during the first $24 \mathrm{~h}$ of life prior to a blood transfusion. Mean OI and OSI were calculated for each neonate and showed a correlation coefficient of 0.952 ( $p<0.0001$; fig. 1a). The scatter plot with all the observations is shown in figure $1 \mathrm{~b}$.

\section{Lambs with MAS and HRF}

Data were obtained from 40 term lambs with asphyxia, meconium aspiration and $\mathrm{PPHN}$. For all $\mathrm{SpO}_{2}$ values, mean OI and OSI for each lamb showed a correlation of 0.948 ( $\mathrm{p}<0.0001$; fig. $2 \mathrm{a}$ ). The scatter plot with all the individual observations is shown in figure $2 \mathrm{~b}$.

\section{Mathematical Relationship between OI and OSI}

For all $\mathrm{SpO}_{2}$ values, the slope of the trend line of the correlation between OI and OSI were represented by the 
following equation: $\mathrm{OI}=1.95 \times \mathrm{OSI}-0.5$. We simplified this equation for practical purposes to $\mathrm{OI}=2 \times$ OSI.

\section{Ability to Predict OI Using OSI}

We subsequently tested the ability of OSI to predict the OI of $\geq 10, \geq 15, \geq 20$, and $\geq 25$. For various mean OI values the corresponding mean OSI values based on the equation $\mathrm{OI}=2 \times$ OSI showed good sensitivity and specificity and a high negative predictive value (table 1 ).

\section{OI, OSI and PVR}

Finally, we compared the mean PVR measurement in each lamb with MAS and HRF. Increasing OI and OSI and decreasing $\mathrm{SpO}_{2}$ were associated with increased PVR (fig. 3). However, both OI and OSI did not correlate well with PVR (correlation coefficient of -0.044 and -0.060 , respectively). Preductal $\mathrm{SpO}_{2}$ showed better correlation with PVR (correlation coefficient of 0.4).

\section{Discussion}

The results from this study demonstrate that OSI, calculated by substituting $\mathrm{SpO}_{2}$ obtained by pulse oximetry for $\mathrm{PaO}_{2}$, can be as accurate as $\mathrm{OI}$ in assessing the severity of HRF in human neonates and lambs with MAS. As expected, neither OI nor OSI demonstrated good correlation with PVR. We have previously shown better correlation between $\mathrm{PaO}_{2}$ and $\mathrm{SpO}_{2}$ with PVR in a lamb model of PPHN induced by antenatal ductal ligation - a model without significant parenchymal lung disease [8]. We speculate that MAP may have different effects on PVR based on the degree of parenchymal lung disease, limiting the ability of OI/OSI to predict PVR.

The high negative predictive value (table 1 ) and the linear nature of the association between OI and OSI in the clinically relevant range of OI (between 4 and 32) make OSI a valuable clinical tool to assess the severity of HRF in the NICU. However, there are several limitations to this study. The location of the pulse oximeter probe (preductal or postductal) will influence OSI and should be taken into consideration. A standardized approach of using preductal $\mathrm{SpO}_{2}$ may improve the usefulness of OSI. The relationship between $\mathrm{SpO}_{2}$ and $\mathrm{PaO}_{2}$ (the oxygen dissociation curve) is altered by the type of hemoglobin (fetal vs. adult - which may be altered after a transfusion), $\mathrm{pH}$, temperature, etc. and may influence the validity of OSI. Lastly, because of the shape of the oxygen dissociation curve, extremely high and very low $\mathrm{SpO}_{2}$ values do not correlate well with $\mathrm{PaO}_{2}$. For exam-
Table 1. Sensitivity, specificity, positive predictive value, and negative predictive value of OSI values to predict the likelihood of OI whose values are twice that of OSI in neonates with HRF and lambs with MAS

\begin{tabular}{|c|c|c|c|c|}
\hline & Sensitivity & Specificity & PPV & NPV \\
\hline \multicolumn{5}{|l|}{ Neonates with HRF } \\
\hline $\mathrm{OI} \geq 10$ and $\mathrm{OSI} \geq 5$ & 0.80 & 0.97 & 0.80 & 0.97 \\
\hline $\mathrm{OI} \geq 15$ and $\mathrm{OSI} \geq 7.5$ & 0.83 & 1 & 1 & 0.99 \\
\hline $\mathrm{OI} \geq 20$ and $\mathrm{OSI} \geq 10$ & 1 & 0.99 & 0.75 & 1 \\
\hline $\mathrm{OI} \geq 25$ and $\mathrm{OSI} \geq 12.5$ & 1 & 0.99 & 0.67 & 1 \\
\hline \multicolumn{5}{|l|}{ Lambs with MAS } \\
\hline $\mathrm{OI} \geq 10$ and $\mathrm{OSI} \geq 5$ & 0.94 & 0.92 & 0.88 & 0.96 \\
\hline $\mathrm{OI} \geq 15$ and $\mathrm{OSI} \geq 7.5$ & 1 & 0.88 & 0.67 & 1 \\
\hline $\mathrm{OI} \geq 20$ and $\mathrm{OSI} \geq 10$ & 1 & 0.97 & 0.89 & 1 \\
\hline $\mathrm{OI} \geq 25$ and $\mathrm{OSI} \geq 12.5$ & 0.71 & 0.94 & 0.71 & 0.94 \\
\hline
\end{tabular}

$\mathrm{PPV}=$ Positive predictive value $\mathrm{NPV}=$ negative predictive value.

ple, an infant with a $\mathrm{PaO}_{2}$ of $65 \mathrm{~mm} \mathrm{Hg}$ (and $\mathrm{SpO}_{2}$ of $98 \%$ ) on $100 \%$ inspired oxygen and $15 \mathrm{~cm} \mathrm{H}_{2} \mathrm{O}$ MAP has an OI of 23 and an OSI of 15.3. If this patient receives inhaled nitric oxide and $\mathrm{PaO}_{2}$ improves to $165 \mathrm{~mm} \mathrm{Hg}$ (with $\mathrm{SpO}_{2}$ of $100 \%$ ), his/her OI will decrease to 9 but the OSI will remain at 15 . The OSI value may theoretically be improved by weaning $\mathrm{FiO}_{2}$ and avoiding extremely high $\mathrm{SpO}_{2}$.

It is conceivable that many subjects who would meet the entry criteria for enrollment in randomized clinical trials for HRF and PPHN are not enrolled due to the inability to obtain serial arterial blood gases within the window defined in the inclusion criteria [1]. In addition, if the bedside provider fails to obtain an arterial blood gas sample and calculate OI, the severity of HRF or $\mathrm{PPHN}$ and the need for intervention (e.g. transfer from a non-ECMO NICU to an ECMO center) may potentially be missed. With the advancement in pulse oximetry technology in recent years, this noninvasive and measure of systemic oxygenation has become the fifth vital sign [11]. We speculate that developing software to integrate $\mathrm{MAP}, \mathrm{FiO}_{2}$ and $\mathrm{SpO}_{2}$ data and display OSI in patients on mechanical ventilation will enable bedside providers to promptly assess the changing severity of HRF and PPHN.

\section{Acknowledgement}

This study was funded by 5R01HD072929-03 (S.L.). 


\section{References}

1 Thomas NJ, Shaffer ML, Willson DF, Shih MC, Curley MA: Defining acute lung disease in children with the oxygenation saturation index. Pediatr Crit Care Med 2010;11:12-17.

$>2$ Neonatal Inhaled Nitric Oxide Study Group: Inhaled nitric oxide in full-term and nearly full-term infants with hypoxic respiratory failure. N Engl J Med 1997;336:597-604.

>3 Clark RH, Kueser TJ, Walker MW, Southgate WM, Huckaby JL, Perez JA, Roy BJ, Keszler M, Kinsella JP: Low-dose nitric oxide therapy for persistent pulmonary hypertension of the newborn. Clinical Inhaled Nitric Oxide Research Group. N Engl J Med 2000;342:469474.

4 Golombek SG, Young JN: Efficacy of inhaled nitric oxide for hypoxic respiratory failure in term and late preterm infants by baseline severity of illness: a pooled analysis of three clinical trials. Clin Ther 2010;32:939-948.
5 Konduri GG, Solimano A, Sokol GM, Singer J, Ehrenkranz RA, Singhal N, Wright LL, Van Meurs K, Stork E, Kirpalani H, et al: A randomized trial of early versus standard inhaled nitric oxide therapy in term and near-term newborn infants with hypoxic respiratory failure. Pediatrics 2004;113(3 Pt 1):559-564.

6 Khemani RG, Patel NR, Bart RD 3rd, Newth CJ: Comparison of the pulse oximetric saturation/fraction of inspired oxygen ratio and the $\mathrm{PaO}_{2} /$ fraction of inspired oxygen ratio in children. Chest 2009;135:662-668.

7 Lakshminrusimha S, Russell JA, Steinhorn RH, Swartz DD, Ryan RM, Gugino SF, Wynn KA, Kumar VH, Mathew B, Kirmani K, et al: Pulmonary hemodynamics in neonatal lambs resuscitated with 21,50 , and $100 \%$ oxygen. Pediatr Res 2007;62:313-318.
8 Lakshminrusimha S, Swartz DD, Gugino SF, Ma CX, Wynn KA, Ryan RM, Russell JA, Steinhorn RH: Oxygen concentration and pulmonary hemodynamics in newborn lambs with pulmonary hypertension. Pediatr Res 2009;66:539-544.

-9 Lakshminrusimha S, Mathew B, Nair J, Gugino SF, Koenigsknecht C, Rawat M, Nielsen L, Swartz DD: Tracheal suctioning improves gas exchange but not hemodynamics in asphyxiated lambs with meconium aspiration. Pediatr Res 2014, DOI: 10.1038/pr.2014.186.

$>10$ Roy A: Estimating correlation coefficient between two variables with repeated observations using mixed effects model. Biom J 2006; 2:286-301.

11 Mower WR, Sachs C, Nicklin EL, Baraff LJ: Pulse oximetry as a fifth pediatric vital sign. Pediatrics 1997;99:681-686. 